\title{
A case with neurological abnormalities caused by Rickettsia raoultii in northwestern China
}

\author{
Zhihui Dong ${ }^{1 \dagger}$, Yicheng Yang ${ }^{1 \dagger}$, Qian Wang ${ }^{2 \dagger}$, Songsong Xie ${ }^{3}$, Shanshan Zhao ${ }^{1}$, Wenbo Tan ${ }^{1}$, Wumei Yuan ${ }^{1}$ and \\ Yuanzhi Wang ${ }^{1 *}$
}

\begin{abstract}
Background: The number of new rickettsial species are rapidly increasing, and increasing numbers of Rickettsia raoultii ( $R$. raoultii) infection cases have been detected in humans. However, neurological abnormalities caused by $R$. raoultii are rarely reported, especially in northwestern China.

Case presentation: A 36-year-old Kazakh shepherd with an attached tick on part temporalis, presented with right eyelid droop, lethargy, fever, headache, fever $\left(38.0-41.0^{\circ} \mathrm{C}\right)$ and erythematous rash. The examination of cerebrospinal fluid (CSF) showed cerebrospinal pressure of $200 \mathrm{~mm} \mathrm{H}_{2} \mathrm{O}$, leukocyte count of $300.0 \times 10^{6} / \mathrm{L}$, adenosine deaminase of $2.15 \mathrm{U} / \mathrm{L}$, and total protein concentration of $0.93 \mathrm{~g} / \mathrm{L}$. The diagnosis of $R$. raoultii infection was confirmed by six genetic markers, and semi-quantified by enzyme-linked immunosorbent assay for rickettsial antigen. The patient gradually recovered after treatment with doxycycline and ceftriaxone. $R$. raoultii DNA was found both in a tick detached from this patient and in $0.18 \%$ (2/1107) of blood samples collected from local shepherds.

Conclusions: This is the first reported case with neurological abnormalities caused by $R$. raoultii in northwestern China. It is vital to detect rickettsial agents both in blood and CSF for tick bite patients with neurological abnormalities. Public health workers and physicians should pay attention to neurological abnormalities caused by Rickettsia.
\end{abstract}

Keywords: Rickettsia raoultii, Neurological abnormalities, Northwestern China

\section{Background}

Rickettsial diseases are prevalent worldwide, although the prevalent organisms differ in different geographical regions [1]. Rickettsia raoultii ( $R$. raoultii) were firstly found in Dermacentor nuttallii (D. nuttallii) ticks in 1999 [2]. Subsequently, it was detected in members of genus Haemaphysalis, Rhipicephalus, Hyalomma and Amblyomma ticks, especially in European and Asian countries [3-7]. In Xinjiang (northwestern China), $R$. raoultii was highly prevalent, and 26.35\% (263/998) Dermacentor genus ticks were molecularly tested positive [8]. In

\footnotetext{
* Correspondence: wangyuanzhi621@126.com

'Zhihui Dong, Yicheng Yang and Qian Wang contributed equally to this work.

${ }^{1}$ School of Medicine, Shihezi University, Shihezi 832002, Xinjiang Uygur

Autonomous Region, China

Full list of author information is available at the end of the article
}

addition, $R$. raoultii infections have also been increasingly detected in humans, and mainly distributed in Europe and Far East of Russia [9-15]. In contrast, only few human infection cases have been reported in China [16-18]. In 2017, twenty-six tick bite patients infected with $R$. raoultii were reported. Their clinical syndrome ranged from asymptomatic infection to severe illness. The nonspecific manifestations were common, and included fever (100\%), malaise (95\%), myalgia (58\%), lymphadenopathy (53\%) and nausea (42\%). Only $5 \%$ of them had rash, and $16 \%$ had eschar [17].

Here we report a case with neurological abnormalities caused by $R$. raoultii infection, which was confirmed using two complementary methods, enzyme-linked immunosorbent assay (ELISA) and polymerase chain reaction (PCR), followed by multi-gene sequencing. Epidemiological and rickettsial surveillance were also conducted in Xinjiang. 


\section{Case presentation}

On June 3, 2017, a 36-year-old previously healthy Kazakh shepherd visited the First Affiliated Hospital of Xinjiang Medical University in Urumqi. He kept a tick detached from left part temporalis, which was identified as a female adult $D$. marginatus by an entomologist and further confirmed based on two tick-specific genetic markers [mitochondrial $16 \mathrm{~S}$ ribosomal DNA (16S rDNA) and cytochrome c oxidase subunit I (COI)] according to previous reports [19]. The patient was initially asymptomatic, but 8 days later, his body temperature fluctuated between 38.0-41.0 (Fig. 1), accompanied by headache, malaise and anorexia. The patient gradually developed right eyelid droop, chest tightness, shortness of breath, lethargy and nausea accompanied by a vomiting 1 day before hospitalization. Cerebrospinal fluid (CSF) obtained through lumbar puncture examination showed cerebrospinal pressure of $200 \mathrm{~mm} \mathrm{H}_{2} \mathrm{O}$ (normal range, 80-180 $\mathrm{mm} \mathrm{H}_{2} \mathrm{O}$ ), leukocyte count of $300.0 \times 10^{6} / \mathrm{L}$ (normal range, $0-100 \times 10^{6} / \mathrm{L}$ ), adenosine deaminase of $2.15 \mathrm{U} / \mathrm{L}$ (normal range, 4-20 U/L), weakly positive Pandy test [20], and protein concentration of $0.93 \mathrm{~g} / \mathrm{L}$ (normal range, $0.15-0.45 \mathrm{~g} / \mathrm{L}$ ). Transient leukocytosis developed after the onset and peaked on day 8 at $20.1 \times 10^{9} / \mathrm{L}$ (normal range, $4-10 \times 10^{9} / \mathrm{L}$ ), with a neutrophilic leukocytosis. Other laboratory findings are shown in Table 1. A blood sample was collected and DNA was extracted using a TIANamp genomic DNA kit (Tiangen Biotechnique Inc., Beijing, China) according to the manufacturer's instructions. Rickettsial DNA was primarily detected by 17 kilodalton antigen $(17-k D a)$, which was Rickettsia-specific genetic marker [19]. The patient was treated with nasogastric or oral doxycycline $100 \mathrm{mg} /$ day and Intravenous (IV) ceftriaxone $2 \mathrm{~g}$ /day for 10 days $[12,17]$. Other symptomatic therapies like antipyretics, IV glycerol and fructose injection and IV mannitol were used as required. The patient was admitted to the intensive care unit for 6 days until fever disappeared and clinical manifestations alleviated. Repeated CSF test and routine blood test were normal. The patient has not experienced recurrence of fever or neurological symptoms after 6 months.

In order to investigate the presence of tick-borne viruses, RNA was extracted using an UItrapure RNA kit (CWBIO, Jiangsu Province, China) and complementary DNA was synthesized with random hexamers, using the Revert Aid First Strand cDNA synthesis kit (TRAN SGEN BIOTECH, Beijing, China) for molecular detection of forest encephalitis virus, severe fever and thrombocytopenia syndrome virus, Crimean-Congo hemorrhagic fever virus and Powassan virus. Meanwhile, the other major tick-borne bacterial pathogens, such as Anaplasma phagocytophilum, Ehrlichia chaffeensis, Babesia spp., Francisella tularensis, Brucella and Borrelia burgorferi sensu lato, was also detected. All these pathogens were tested negative by PCR. To further determine the Rickettsia species, Rickettsia was molecularly detected by other five Rickettsia-specific genetic markers [surface cell antigen 4 (sca4); citrate synthase $(g l t \mathrm{~A})$; cell surface antigen 1 (sca1); outer membrane proteins A $(o m p \mathrm{~A})$; outer membrane proteins $\mathrm{B}(o m p \mathrm{~B})]$ as previously described, and $R$. raoultii was identified by sequencing [19]. Simultaneously, $R$. raoultii was detected in the feeding tick detached from the patient's part temporalis using two Rickettsia-specific genetic markers (Sca4 and ompA). BLASTn (http://blast.ncbi.nlm.nih. gov/Blast.cgi) analysis revealed that the six gene fragments of $R$. raoultii had nucleotide identity of 99.5$100 \%$ with the reference $R$. raoultii strain Khabarovsk genome (accession number: CP010969) (Fig. 2). $R$. raoultii detected in the feeding $D$. marginatus tick

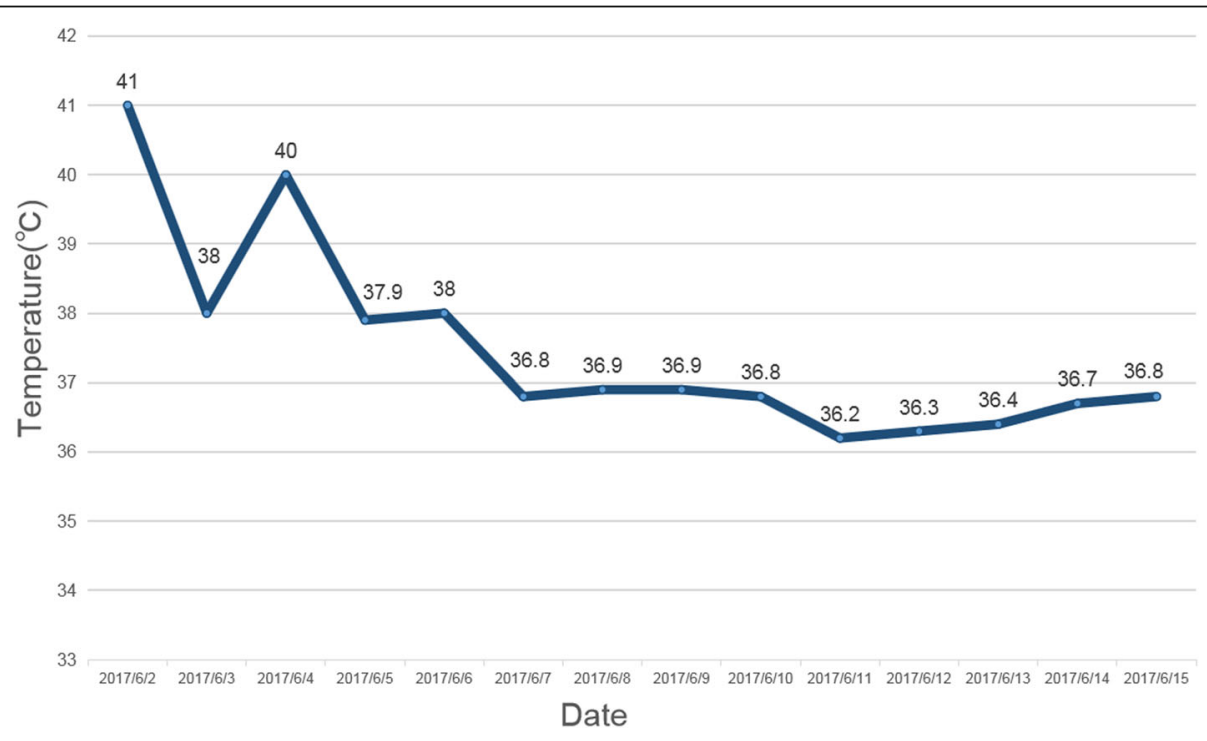

Fig. 1 Change in patient's body temperature 
Table 1 Other laboratory findings from the patient

\begin{tabular}{|c|c|c|c|}
\hline \multicolumn{4}{|l|}{ Laboratory findings } \\
\hline Laboratory findings & & results & normal range \\
\hline \multirow[t]{5}{*}{ Hemogram test } & A white blood cell count & $20.1 \times 10^{9} / \mathrm{L}$ & $4-10 \times 10^{9} / \mathrm{L}$ \\
\hline & Neutrophil count & $18.03 \times 10^{9} / \mathrm{L}$ & $1.4-7 \times 10^{9} / \mathrm{L}$ \\
\hline & Lymphocyte count & $0.82 \times 10^{9} / \mathrm{L}$ & $1.2-3.5 \times 10^{9} / \mathrm{L}$ \\
\hline & Hemoglobin level & $122 \mathrm{~g} / \mathrm{L}$ & $110 \sim 160 \mathrm{~g} / \mathrm{L}$ \\
\hline & Platelet count & $174 \times 10^{9} / \mathrm{L}$ & $100-300 \times 10^{9} / \mathrm{L}$ \\
\hline \multirow[t]{15}{*}{ Blood biochemistry } & Albumin & 29.26umol/L & 35-55umol/L \\
\hline & Total bilirubin & 7.35umol/L & 2-28umol/L \\
\hline & Glutamic-pyruvic transaminase (ALT) & $74.72 \mathrm{u} / \mathrm{L}$ & 0-40u/L \\
\hline & Glutamic-oxaloacetic transaminase (AST) & $56.64 u / L$ & 0-40u/L \\
\hline & Creatine kinase (CK) & $330 \mathrm{IU} / \mathrm{L}$ & $25-200 \mathrm{IU} / \mathrm{L}$ \\
\hline & Potassium ion & $3.29 \mathrm{mmol} / \mathrm{L}$ & $3.5-5.5 \mathrm{mmol} / \mathrm{L}$ \\
\hline & Uric aci (UA) & 94umol/L & 120-440umol/L \\
\hline & Hypersensitive C-reactive protein & $63.401 \mathrm{mg} / \mathrm{L}$ & $0-6 \mathrm{mg} / \mathrm{L}$ \\
\hline & Interleukin 6 & $41.910 \mathrm{Pg} / \mathrm{mL}$ & $<7 \mathrm{Pg} / \mathrm{mL}$ \\
\hline & Erythrocyte sedimentation Rate (ESR) & $54.00 \mathrm{~mm} / \mathrm{h}$ & $0-15 \mathrm{~mm} / \mathrm{h}$ \\
\hline & a1-acidic glycoprotein & $1.56 \mathrm{~g} / \mathrm{L}$ & $0.51-1.17 \mathrm{~g} / \mathrm{L}$ \\
\hline & Transferrin (TRF) & $1.43 \mathrm{~g} / \mathrm{L}$ & $2.02-3.36 \mathrm{~g} / \mathrm{L}$ \\
\hline & D-dimer & $789.0 \mathrm{ng} / \mathrm{ml}$ & $<280 \mathrm{ng} / \mathrm{ml}$ \\
\hline & Free thyroxine & $10.66 \mathrm{pmol} / \mathrm{L}$ & $12-22 \mathrm{pmol} / \mathrm{L}$ \\
\hline & Free triiodothyronine & $2.66 \mathrm{pmol} / \mathrm{L}$ & 3.1-6.8 pmol/L \\
\hline \multirow[t]{2}{*}{ Routine urine } & Urine protein & Positive(+ 2) & negative \\
\hline & Urine acetone bodies & Positive(+ 2) & negative \\
\hline
\end{tabular}

detached from the patient was identical to those amplified from the patient.

To determine rickettsial antigen content at different stages of treatment in the patient's blood, heparinized blood samples obtained from the patient 1 and 7 days after admission were tested using human rickettsia ELISA kits according to the manufacturer's instructions (Shanghai enzyme-linked immunization, Shanghai, China). Rickettsial antigen content gradually decreased after treatment (the results were 33.98 $\mathrm{pg} / \mathrm{ml}$ after first day of hospitalization and $17.78 \mathrm{pg} / \mathrm{ml}$ after seventh day of antibiotic therapy, respectively).

To further investigate the prevalence of rickettsial infection in shepherds, 1107 blood samples were collected from the local human population in Manasi County, Xinjiang. DNA was extracted from anti-coagulated blood samples as described above. PCR was performed to amplify rickettsial Sca1 or ompA fragments, followed by sequencing [19]. Two $R$. raoultii and one $R$. slovaca DNAs were detected (Fig. 2). Fifteen nucleotide sequences have been deposited in GenBank [17kDa: MG190332; gltA: MG190324; sca1: MG811838, MK562056, MK535095, MG190331; sca4: MG190326, MK721054; ompA: MG190325, MK721055MK721057; ompB: MH036479; 16srDNA: TMK813858; COI: TMK813859].

\section{Discussion and conclusions}

It is well known that Q fever, spotted fever group (SFG) and typhus group rickettsial infection may cause central nervous system infection [21]. Among SFG Rickettsia, $R$. rickettsii, $R$. conorii, $R$. helvetica, Candidatus $R$. tarasevichiae and $R$. japonica have documented association with meningitis [21-24]. In China and Europe, 2 Patients infected with $R$. raoultii were reported to show meningeal syndrome, respectively $[17,25]$. In this study, the patient showed right eyelid droop, lethargy, fever, headache, high cerebrospinal pressure and leukocytosis in CSF after bitten by $D$. marginatus tick. Our study has a limitation related to detection of Rickettsia DNA in blood but not in CSF sample. As for biochemical parameters in blood and CSF is unspecific to patients with $R$. raoultii infection, it is vital to detect rickettsial agents both in blood and CSF for tick bite patients with neurological abnormalities.

The previous recommended therapeutic regimen for rickettsiosis is administration of doxycycline or chloramphenicol [26]. In this study, the patient recovered after treatment with doxycycline \& ceftriaxone. This finding indicates that doxycycline combined with ceftriaxone should be recommended when the tick bite patient shows neurological abnormalities caused by rickettsial infection. 


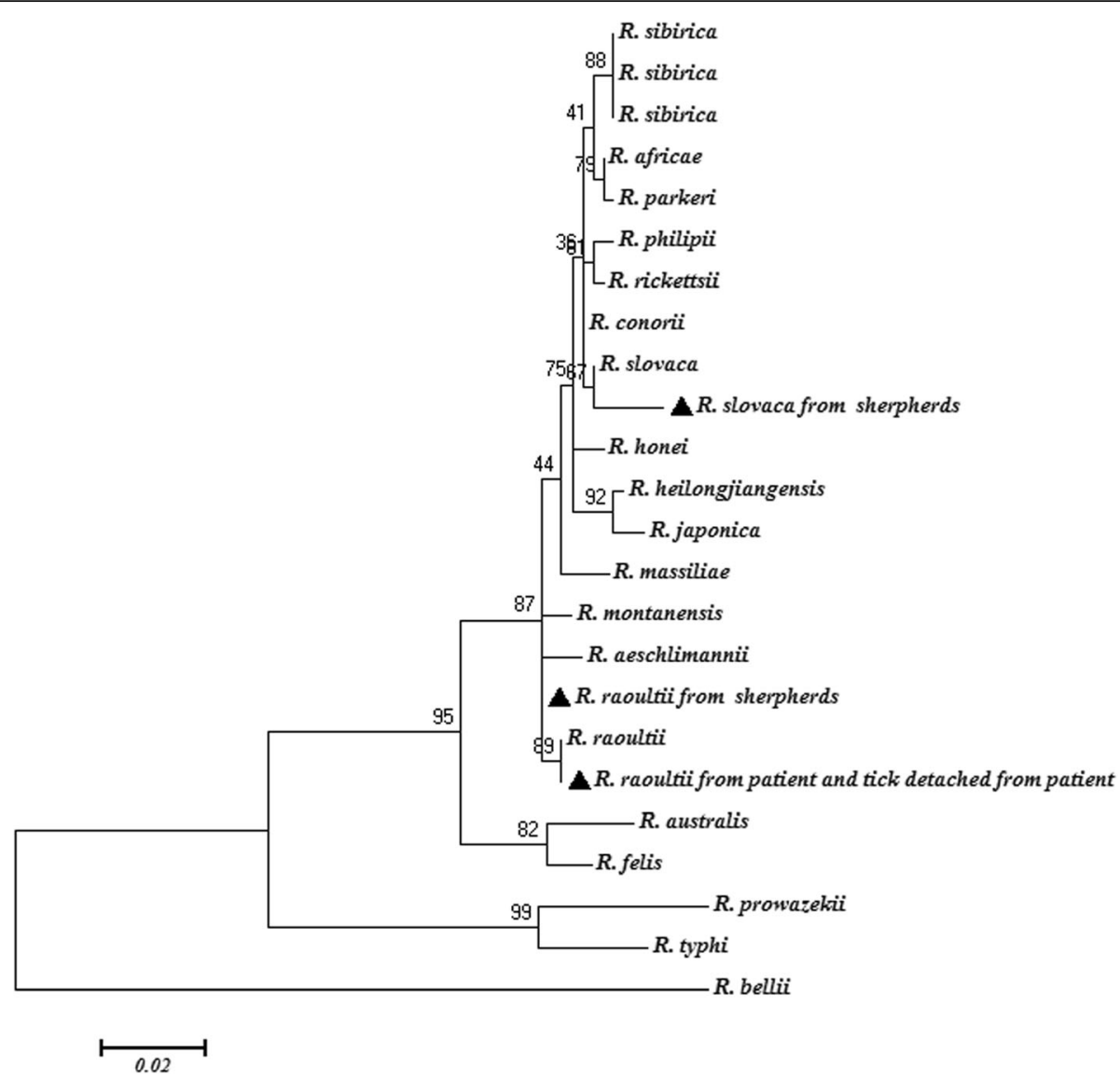

Fig. 2 Phylogenetic tree of 17-kDa-gltA-sca1-sca4-ompA-ompB concatenated sequences of $R$. raoultii in blood from patient, tick detached from patient and shepherds $(\boldsymbol{\Delta})$. The target nucleotide sequences were compared to sequences that were available in public databases using BLAST (http://blast.ncbi.nlm.nih.gov/Blast.cgi). The tree was constructed on the basis of maximum-likelihood (ML; 1000 bootstrap replicates) of concatenated sequence data of six genes (17-kDa-gltA-sca1-sca4-ompA-ompB) using Molecular Evolutionary Genetics Analysis (MEGA, version 7.0; http://www.megasoftware.net/). The sequences of $R$. bellii were used as the outgroup

In this study, two $R$. raoultii $(0.18 \%, 2 / 1107)$ and one $R$. slovaca $(0.09 \%, 1 / 1107)$ were molecularly detected in local shepherds. In addition, the prevalence of SFG Rickettsia in ticks was high in Xinjiang [8]. Therefore, public health workers and physicians need to be aware of the wide distribution and clinical complexity of rickettsial infection, especially higher risk for tick exposure.

\section{Abbreviations}

16S rDNA: mitochondrial 16S ribosomal DNA; 17-kDa: 17 kilodalton antigen; COl: cytochrome c oxidase subunit I; CSF: Cerebrospinal fluid; ELISA: Enzymelinked immunosorbent assay; gltA: citrate synthase; MEGA7: Molecular Evolutionary Genetics Analysis 7; ompA: outer membrane proteins A: ompB: outer membrane proteins $B$; PCR: polymerase chain reaction; $R$. raoultii: Rickettsia raoultii; sca1: cell surface antigen 1; sca4: surface cell antigen 4; SFG: spotted fever group

\section{Acknowledgments}

Not applicable.

\section{Authors' contributions}

YZW conceived and designed the study. SSZ and QW critically revised the manuscript. ZHD and YCY completed the experiment, analyzed the data and drafted the manuscript. SSX treated the patient, and carried out the clinical diagnosis, WBT and WMY conducted molecular analyses. All authors read and approved the final manuscript.

\section{Funding}

This research was supported in part by the National Key Research and Development Program of China (2018ZX10101002-002-007) and National Natural Science Foundation of China (81560338). The funding source had no influence in the design of the study and collection, analysis, and interpretation of data and in writing the manuscript.

\section{Availability of data and materials}

All data generated or analyzed during this study are included in this published article and its supplementary information files.

\section{Ethics approval and consent to participate}

The research was approved by the First Affiliated Hospital of Shihezi Medical University. (Letter Number: 2017-112-03). Written informed consent was obtained for all research participants.

\section{Consent for publication}

Written informed consent was obtained from the patient for publication of this Case Report and any accompanying images. A copy of the written consent is available for review by the Editor of this journal.

Competing interests

The authors declare that they have no competing interests. 


\section{Author details}

'School of Medicine, Shihezi University, Shihezi 832002, Xinjiang Uygur Autonomous Region, China. ${ }^{2}$ Kaifeng Central Hospital, Henan 475000, China. ${ }^{3}$ The First Affiliated Hospital of Shihezi University Medical College, Shihezi 832002, China

Received: 27 May 2019 Accepted: 27 August 2019

Published online: 11 September 2019

\section{References}

1. Misra UK, Kalita J, Mani VE. Neurological manifestations of scrub typhus. J Neurol Neurosurg Psychiatry. 2014;86(7):761-6.

2. Rydkina E, Roux V, Rudakov N, Gafarova M, Tarasevich I, Raoult D. New Rickettsiae in ticks collected in territories of the former soviet union (statistical data included). Emerg Infect Dis. 1999;5(6):811-4.

3. Mediannikov O, Matsumoto K, Samoylenko I, Drancourt M, Roux V, Rydkina E, et al. Rickettsia raoultii sp. nov., a spotted fever group rickettsia associated with Dermacentor ticks in Europe and Russia. Int J Syst Evol Microbiol. 2008:58:1635-9.

4. Silaghi C, Hamel D, Thiel C, Pfister K, Pfeffer M. Spotted fever group Rickettsiae in ticks. Germany Emerg Infect Dis. 2011;17:890-2.

5. Márquez FJ, Rojas A, Ibarra V, Cantero A, Rojas J, Oteo JA, et al. Prevalence data of Rickettsia slovaca and other SFG Rickettsiae species in Dermacentor marginatus in the southeastern Iberian Peninsula. Ann N Y Acad Sci. 2010; 1078(1):328-30

6. Nijhof AM, Bodaan C, Postigo M, Nieuwenhuijs H, Opsteegh M, Franssen L, et al. Ticks and associated pathogens collected from domestic animals in the Netherlands. Vector Borne Zoonotic Dis. 2007;7:585-95.

7. Sumrandee C, Hirunkanokpun S, Doornbos K, Kitthawee S, Baimai V, Grubhoffer $\mathrm{L}$, et al. Molecular detection of Rickettsia species in Amblyomma ticks collected from snakes in Thailand. Ticks Tick Borne Dis. 2014;5:632-40.

8. Song S, Chen C, Yang M, Zhao S, Wang B, Hornok S, et al. Diversity of Rickettsia species in border regions of northwestern China. Parasit Vectors. 2018;11(1):634

9. Ibarra V, Oteo JA, Portillo A, et al. Rickettsia slovaca infection: DEBONEL/ TIBOLA. Ann N Y Acad Sci. 2006;1078(1):206-14.

10. Angelakis E, Pulcini C, Waton J, Imbert P, Socolovschi C, Edouard S, et al. Scalp eschar and neck lymphadenopathy caused by Bartonella henselae after tick bite. Clin Infect Dis. 2010;50(4):549-51.

11. Sekeyova Z, Subramanian G, Mediannikov O, Diaz MQ, Nyitray A, Blaskovicova $\mathrm{H}$, et al. Evaluation of clinical specimens for Rickettsia, Bartonella, Borrelia, Coxiella, Anaplasma, Franciscella and Diplorickettsia positivity using serological and molecular biology methods. FEMS Immunol Med Microbiol. 2012;64(1):82-91.

12. Switaj K, Chmielewski T, Borkowski P, Tylewska-Wierzbanowska S, OlszynskaKrowicka M. Spotted fever rickettsiosis caused by Rickettsia raoultii-case report. Przegl Epidemiol. 2012;66:347-50.

13. Dubourg G, Socolovschi C, Del Giudice P, Fournier PE, Raoult D. Scalp eschar and neck lymphadenopathy after tick bite: an emerging syndrome with multiple causes. Eur J Clin Microbiol Infect Dis. 2014;33:1449-56.

14. Zaharia M, Popescu CP, Florescu SA, Ceausu E, Raoult D, Parola P, et al. Rickettsia massiliae infection and SENLAT syndrome in Romania. Ticks Tick Borne Dis. 2016;7:759-62.

15. Parola P, Rovery C, Rolain JM, Brouqui P, Davoust B, Raoult D. Rickettsia slovaca and $R$. raoultii in tick-borne rickettsioses. Emerg Infect Dis. 2009;15:1105-8.

16. Jia $N$, Zheng $Y C, M a L$, Huo QB, Ni XB, Jiang BG, et al. Human infections with Rickettsia raoultii. China Emerg Infect Dis. 2014;20(5):866-8

17. Li H, Zhang PH, Huang Y, Du J, Cui N, Yang ZD, et al. Isolation and identification of Rickettsia raoultii in human cases: a surveillance study in 3 medical centers in China. Clin Infect Dis. 2017.

18. Yin X, Guo S, Ding C, Cao M, Kawabata H, Sato K, et al. Spotted fever group Rickettsiae in Inner Mongolia, China, 2015-2016. Emerg Infect Dis. 2018 Nov,24(11):2105-7.

19. Zhao $S$, Yang M, Jiang M, Yan B, Zhao S, Yuan W, et al. Rickettsia raoultii, and Rickettsia sibirica, in ticks from the long-tailed ground squirrel near the China-Kazakhstan border. Exp Appl Acarol. 2019;77(3):425-33.

20. Bullock FN, Fleischhacker HH. Interpretation of the pandy test. Acta Psychiatr Neurol Scand. 2010;26(2):149-53.

21. Araki M, Takatsuka K, Kawamura J, Kanno Y. Japanese spotted fever involving the central nervous system: two case reports and a literature review. J Clin Microbiol. 2002;40:3874-6. https://doi.org/1 0.1128/JCM.40.10.3874-3876.2002.
22. Nilsson $\mathrm{K}$, Elfving KP, Hlson C. Rickettsia helvetica in patient with meningitis, Sweden, 2006. Emerg Infect Dis. 2010;16(3):490-2.

23. Jia N, Zheng YC, Jiang JF, Ma L, Cao WC. Human infection with Candidatus Rickettsia tarasevichiae. N Engl J Med. 2013:369(12):1178-80.

24. Igolkina Y, Krasnova E, Rar V, Savelieva M, Epikhina T, Tikunov A, et al. Detection of causative agents of tick-borne rickettsioses in Western Siberia, Russia: identification of Rickettsia raoultii, and Rickettsia sibirica DNA in clinical samples. Clin Microbiol Infect. 2017; S1198743X17302926.

25. Botelho-Nevers E, Socolovschi C, Raoult D, Parola P. Treatment of Rickettsia spp. infections: A review. Expert Rev Anti Infect Ther. 2012;10(12):1425.

\section{Publisher's Note}

Springer Nature remains neutral with regard to jurisdictional claims in published maps and institutional affiliations.
Ready to submit your research? Choose BMC and benefit from:

- fast, convenient online submission

- thorough peer review by experienced researchers in your field

- rapid publication on acceptance

- support for research data, including large and complex data types

- gold Open Access which fosters wider collaboration and increased citations

- maximum visibility for your research: over $100 \mathrm{M}$ website views per year

At $\mathrm{BMC}$, research is always in progress.

Learn more biomedcentral.com/submissions 